\title{
Fluent and nonfluent forms of transfer in reading: Words and their message
}

\author{
HEATHER J. FAULKNER and BETTY ANN LEVY \\ McMaster University, Hamilton, Ontario, Canada
}

\begin{abstract}
In two experiments, we examined transfer to the reading of a normal text from a prior reading of that intact text or from a prior reading of a scrambled word version of the passage. In Experiment 1, we studied good and poor readers in Grade 4; in Experiment 2, high- and low-ability undergraduate readers. Good readers at both ages showed rereading benefits only when the prior reading was of the intact text, with no reliable benefit from experience with words only. The poorer readers showed reliable rereading benefits even when only the words, in a scrambled order, were read on the first encounter. The results are discussed in terms of two forms of transfer: nonfluent reading transfer when attention must be focused on word recognition, and fluent rereading transfer when word recognition is skilled so that attention can be focused on text processing.
\end{abstract}

Much has been learned over the past decade about transfer from one reading encounter to another. Transfer is found when one repeatedly reads the same text and becomes faster with each reading, without any compromise in comprehension (see Levy, 1993, for a review). Reading speed acts as an implicit indicator that the memorial representations laid down during earlier readings have been recruited to facilitate later reading (Cohen \& Squire, 1980; Kolers, 1975). However, there still remains some ambiguity regarding the relation between transfer at the word level and transfer at higher linguistic levels. The experiments reported here addressed variables that could alter the linguistic level that mediates transfer across repeated readings. The central issue is the nature of the representation that mediates fluent reading as one gains reading experience. We draw a contrast between transfer when reading is difficult and nonfluent, and transfer when reading is easier and more fluent.

During the development of reading skill, repeated experiences with printed words are critical to setting up the lexical/orthographic representations that are accessed during fluent reading. However, as the child begins to read words in context, one can ask how these word representations become organized within the conceptual framework of the message of the text. This question has been

We thank Clint Davis and the Hamilton-Wentworth Roman Catholic Separate School Board for their help in providing access to schools. We also thank the principals, teachers, parents, and children for their cooperation and participation in Experiment 1 . We gratefully acknowledge the financial assistance provided by grants from the Ontario Mental Health Foundation (Experiment I) and the Natural Sciences and Engineering Research Council of Canada (Experiment 2) to the second author. These experiments formed part of the PhD dissertation of the first author when she was supported by a studentship from the Ontario Mental Health Foundation. She is now at the Hospital for Sick Children, Toronto. Correspondence concerning this article should be addressed to B. A. Levy, Department of Psychology, McMaster University, Hamilton, ON L8S 4K1, Canada (e-mail: levy@mcmaster.ca). addressed in studies of adult fluent reading and in studies of remedial treatment of reading problems in beginning readers. Using fluent adult readers, Carr, Brown, and Charalambous (1989) studied the amount of transfer to reading short passages, comparing transfer from a prior reading of the randomized words of these passages with that from a prior reading of the passages intact. The logic was that because the words were repeated in both cases, any transfer at the word level should be equivalent for the wordsonly and the passage-intact conditions. If transfer was mediated by higher level text processes, the randomizedword condition should show little or no transfer to story reading. The results supported the view that transfer was mediated at the word level, because transfer in the randomizedword condition was equivalent to that in the passage condition.

Carr et al.'s (1989) findings were inconsistent with other studies in the literature that concluded that words read in context were represented in memory in that context because changing the context destroyed the transfer benefit. For example, when words were read in a paragraph, there was no transfer benefit when those words were reread in a word identification task (e.g., lexical decision, perceptual identification), even though there was transfer when the words were first read in a word task (e.g., Levy \& Kirsner, 1989; Oliphant, 1983). This result suggested that words read in a paragraph were represented in memory with their context, and that the individual words taken out of this context were unable to recruit the memory representations during transfer. That is, transfer could not cross linguistic levels. Further, Levy and Burns (1990) reported decrements in transfer when the initial and subsequent texts differed in linguistic organization. Transfer to reading a normal story was examined following the reading of versions that were scrambled at the paragraph, sentence, or word levels. The amount of transfer observed decreased across these three conditions as more and more of the linguistic structure was lost in the 
scrambling. Again, these results are inconsistent with the word-level transfer reported by Carr et al.; clearly, higher linguistic levels influenced transfer.

A potential explanation of the discrepancy between the findings of Carr et al. (1989) and Levy and Burns (1990) was offered by Carlson, Alejano, and Carr (1991). They suggested that the Carr et al. experiments may have focused subjects' attention at the individual word level, whereas the Levy and Burns experiments focused subjects' attention on message processing. Carlson et al. tested this explanation by asking subjects to read either in a strict word-by-word fashion, with no attempt to relate words, or in a message-processing mode, following Levy and Burns. The word-by-word instruction led to transfer from scrambled words to reading text, replicating Carr et al., whereas the message orientation led to no transfer from words to text rereading, following Levy and Burns. These data support the view that texts can be read in different ways and that the representation that is laid down in memory reflects this reading orientation. The match between the level of the memorial representation and the level of processing required by the transfer task determines the type of transfer observed.

Yet although this conclusion appears to resolve the conflicting findings reported by Carr et al. (1989) and other researchers (e.g., Levy \& Burns, 1990; Levy \& Kirsner, 1989; Oliphant, 1983), it leaves open the question of what determines the reading orientation that wil! be used. Clearly, strong instructions regarding reading strategy are one factor. However, Levy, Masson, and Zoubek (1991) found that simply focusing attention on careful print analysis did not produce word-level transfer. When readers were required to focus on the individual words in order to cross out Greek letters scattered throughout the text, they did not show any more word-level transfer than did subjects who were given a message orientation. Thus, it is unclear that attentional focus to careful print analysis of the individual words will always lead to word-level transfer, as suggested by the work of Carlson et al. (1991).

The developmental literature provides a hint regarding a possible mechanism whereby a focus on the words of a text will lead to word-level, rather than text-level, transfer across experiences. In several early studies, it was reported that young children who were experiencing difficulty in learning to read benefited from practice in repeatedly reading the same passage (Dahl, 1979; Samuels, 1979). Samuels argued that across repeated readings children automated their word recognition skills and that this benefit crossed linguistic contexts, as was indicated by the finding that later stories in the training sequences were read faster than earlier stories, even the first time they were encountered. Further, Rashotte and Torgesen (1985) reported that benefits from training with repeated readings only generalized to new texts when the texts shared many words (see also Dowhower, 1987). The important points here are that the transfer found in these studies appeared to be mediated at the individual word level since it crossed reading contexts, and this transfer was observed in poor readers who struggled with word recognition.

Following this lead, Faulkner and Levy (1994) suggested that when word recognition is difficult, transfer occurs at the individual word level and will cross linguistic contexts, following Carr et al. (1989). This result occurred in the Faulkner and Levy study when poor readers in Grades 3 and 6 , who had difficulty reading the words, read two different stories that shared many words. Even though the words were repeated in stories conveying different messages, the word overlap was sufficient to mediate transfer to the second story. However, under the same conditions, there was no transfer between two stories that shared many words when the subjects were good readers. For them word recognition was easy and transfer was observed only if there was message overlap, following the findings of Levy and her colleagues with fluent adult readers. Thus Faulkner and Levy observed two forms of transfer: the fluent transfer observed with good readers that appears to be mediated through higher order text structures, and the nonfluent transfer observed with poor readers that is mediated by individual word representations.

Here we report two experiments that further bridge the findings from the adult and the developmental literatures. In the first experiment, good and poor readers in Grade 4 participated in a repeated reading task like that used by Levy and Burns (1990). These children first read either a normal story or a scrambled version of the story, and then in both conditions they read the normal version. Following the arguments of Faulkner and Levy (1994), good readers should show a transfer benefit only in the normal conditions, whereas poor readers should show transfer even in the scrambled word condition. This experiment replicated with children the conditions studied in the adult literature (Levy \& Burns, 1990). In the second experiment, we compared transfer from normal and scrambled text readings when fluent adult readers were reading texts that were easy or difficult for them. This experiment provided an adult analogue to the child studies of Faulkner and Levy. Together the experiments provide further evidence that the ease or difficulty of word recognition determines the focus of attention and therefore the level of the representation laid down during the reading task.

\section{EXPERIMENT 1}

\section{Method}

Subjects. Forty-eight children in Grade 4 participated in this study. Twenty-four students (13 females, 11 males) with standard scores of 108 or above on the word identification subtest of the Wide Range Achievement Test (WRAT - R, standardized with a mean of 100 and an $S D$ of 10 ) formed the good reader group. Their mean score was $115.08(S D=4.02$; range, $108-122)$. Twenty-four students ( 12 females, 12 males) with standard scores between 60 and 90 on the WRAT-R formed the poor reader group. Their mean score was $77.29(S D=7.72$; range, 61-88). 
Table 1

Mean Reading Times (in Seconds) in Experiment 1

\begin{tabular}{|c|c|c|c|c|c|c|}
\hline \multirow[b]{3}{*}{ Readers } & \multicolumn{6}{|c|}{ Story } \\
\hline & \multicolumn{2}{|c|}{$\begin{array}{c}\text { First } \\
\text { (Normal) }\end{array}$} & \multicolumn{2}{|c|}{$\begin{array}{c}\text { Second } \\
\text { (After Normal) }\end{array}$} & \multicolumn{2}{|c|}{$\begin{array}{c}\text { Second } \\
\text { (After Scrambled }\end{array}$} \\
\hline & $M$ & $S D$ & $M$ & $\overline{S D}$ & $M$ & $S D$ \\
\hline Good & 52.93 & 12.01 & 46.26 & 10.13 & 52.60 & 10.44 \\
\hline Poor & 126.48 & 53.41 & 100.23 & 42.78 & 118.12 & 53.33 \\
\hline
\end{tabular}

Materials and Design. The children were given 140-word stories to be read aloud twice in succession as quickly as possible, while also reading for meaning in preparation for comprehension questions. Reading time per story was the measure of interest. In both experimental conditions, the version of the story that was read second was always in a normal form. What varied was the structure of the first version read, so that the conditions were defined by the passage structure on the first reading. In the scrambled words condition, the first version consisted of a randomization of the words from the normal story, reordered with the restriction that no two successive words could convey a meaningful message. In the normal condition, the normal story was read on both readings. The stories were at or above the Grade 4 level ( 1 at 4 th, 1 at 6 th, and 2 at 5 th grade, according to the Flesch-Kincaid analysis; Flesch, 1948). The randomized words in the scrambled versions were arranged into sentences and paragraphs that mimicked normal stories. The order of presentation of the conditions was counterbalanced across subjects, and each story was used equally often in each condition for both good and poor reader groups, thus ensuring that there were no differences in materials for any of the statistical contrasts reported here. Four comprehension questions were asked and answered orally after the subject read each pair of stories. These questions were used to orient the children to read for meaning and were not designed as useful measures of comprehension, so no comprehension data are reported.

Procedure. The children were tested individually in two sessions. They were told that some of the stories would not make sense but that they should read them carefully because reading these "strange" stories might help them read the next story. The experimenter started a millisecond timer when the child read the first word of the text and stopped it when the last word was read. The children were encouraged to beat their previous time. If a child hesitated on a word, the word was provided within a few seconds in order to maintain comprehension and so that reading times would not be inflated by long pauses to decode unfamiliar words. A short practice passage was given prior to the experimental texts. The comprehension questions were asked following reading of both versions of a story.

\section{Results and Discussion}

The mean reading times on the second reading in each condition were used for all analyses. A $2 \times 2$ analysis of variance with the variables of group (good/poor readers) and conditions (normal/scrambled version on the first reading) revealed reliable main effects of both variables that were qualified by their interaction $[F(1,46)=7.00$, $\left.M S_{\mathrm{e}}=112.9, p<.01\right]$. (See Table 1 for the means for this interaction.) To determine whether reliable transfer occurred on the second reading, the reading times for the second stories (always in normal form) were compared with the reading times for the first stories when they were in the normal format. This comparison indicates the dif- ference in reading time for a normal story when it was read first versus when it was read second, following a prior reading of the intact passage or a scrambled word version of the passage (i.e., it is a savings measure). For the good readers, the second reading was reliably faster than the first reading in the normal $[t(23)=10.28]$, but not in the scrambled $(t<1)$, condition. Thus like the adult fluent readers studied by Levy and Burns (1990), these good readers showed transfer at the text level, but no reliable transfer at the individual word level.

The same contrasts for the poor readers showed faster reading of the second text when the first passage was the normal text $[t(23)=9.01, p<.01]$, and when the first passage consisted of scrambled words $[t(23)=2.44, p<$ $.05]$. Thus, repetition of the words alone was enough to mediate transfer for these poor readers. The transfer benefits were less in the scrambled words condition than in the normal condition $[t(23)=4.22, p<.01]$, showing some additional benefit of repetition of the message. In this experiment, good readers produced transfer mediated by the message, but not by individual words, just as in the adult results reported by Levy and Burns (1990). However, poor readers showed the word-level transfer originally reported by Carr et al. (1989). We suggest that the good readers show fluent reading transfer that is mediated by text-level processes, whereas the poor readers demonstrate a nonfluent form of reading transfer that is mediated by word-level processes.

\section{EXPERIMENT 2}

The two types of transfer observed in Experiment 1 resembled the text- and word-level transfer reported for adult readers (Levy \& Burns, 1990; Carr et al., 1989, respectively). Carlson et al. (1991) produced this same dual pattern when adult readers' attention was focused on word-by-word reading versus message processing. In Experiment 2 , we attempted to produce a more naturalistic occurrence of this focus of attention manipulation, by asking college students of high and lower reading abilities to read texts that were easy and texts that were challenging for their reading ability. The manipulation to be reported here was whether the first passage read was the intact text or a scrambled word version of the text. The second passage read was always the normal text. Thus, the contrast in main conditions was exactly the one used in Experiment 1 . The additional manipulation was the use of easy versus difficult passages in order to tax reading ability in these college students. It was expected that the good readers would show transfer mediated by text-level processes, because even the difficult texts would not tax their word recognition skills. However, the low-ability group was expected to show the word-level transfer, at least when reading the difficult passages. In order to detect reading level differences among these more skilled adult readers, in Experiment 2 we used a line-by-line presentation method, with reading time per line as the mea- 
Table 2

Mean Reading Times (in Seconds) in Experiment 2

\begin{tabular}{|c|c|c|c|c|c|c|c|}
\hline \multirow[b]{3}{*}{ Ability } & \multirow[b]{3}{*}{ Stories } & \multicolumn{6}{|c|}{ Story } \\
\hline & & \multicolumn{2}{|c|}{$\begin{array}{c}\text { First } \\
\text { (Normal) }\end{array}$} & \multicolumn{2}{|c|}{$\begin{array}{c}\text { Second } \\
\text { (After Normal) }\end{array}$} & \multicolumn{2}{|c|}{$\begin{array}{c}\text { Second } \\
\text { (After Scrambled) } \\
\end{array}$} \\
\hline & & $M$ & $S D$ & M & $S D$ & $M$ & $S D$ \\
\hline \multirow[t]{2}{*}{ High } & Easy & 72.89 & 12.97 & 67.55 & 12.97 & 76.18 & 19.61 \\
\hline & Difficult & 86.95 & 20.25 & 80.33 & 16.62 & 84.15 & 16.91 \\
\hline \multirow[t]{2}{*}{ Low } & Easy & 84.66 & 18.83 & 75.16 & 14.99 & 81.41 & 17.10 \\
\hline & Difficult & 104.80 & 29.63 & 90.66 & 24.65 & 95.01 & 19.36 \\
\hline
\end{tabular}

sure. This method has been shown to be sensitive to differences in reading times as the reader progresses through the text (Levy et al., 1995).

\begin{abstract}
Method
Subjects. Forty-eight undergraduate volunteers participated for course credit. A median split of these subjects' scores on the WRAT-R word identification subtest was used to form the highand low-ability groups. The high-ability group consisted of 24 students ( 17 females, 7 males) with standard scores on the WRAT-R of 104 and above. Their mean score was $111.25(S D=5.80$; range, 104-126). The low-ability group consisted of 24 students (17 females, 7 males) whose standard scores on the WRAT-R were 103 or below. Their mean score was 94.17 ( $S D=8.32$; range, $72-103$ ).

Materials and Design. The subjects were given 200-word passages that contained 20 or 21 lines to be read aloud, twice in succession. Line-by-line presentation was controlled by the reader through a keypress on the computer keyboard. The first keypress started the computer clock when the first line appeared on the monitor. Each subsequent keypress presented the next line below the previous one on the computer screen, until all 20/21 lines were displayed. The computer recorded the time of each keypress. Comprehension questions following the second reading of each passage oriented the reader to read for meaning, but no data on these questions were collected. The basic data were the reading times per line for each reading. The easy passages were adapted from texts taken from the Starting Points in Reading Series. All passages were at or below the Grade 7 level when analyzed with the Flesch-Kincaid formula. The difficult passages were adapted from texts taken from the reading comprehension subtests of the Graduate Record Exam and the Student Achievement Tests. The difficult stories were above the Grade 12 level according to the Flesch-Kincaid formula. Each subject read a passage in each of the two basic conditions, where the first reading varied (normal text or scrambled words) but the second reading always being of the normal text. ${ }^{2}$ Materials were counterbalanced across subjects so that every passage at each level of difficulty was tested equally often in each condition, for both reader groups. This counterbalancing ensured that there were no differences in materials for any of the statistical comparisons for each level of difficulty.

Procedure. The subjects were instructed essentially as in Experiment 1 , except that they were told about the line-by-line presentation and were given a practice passage to familiarize them with the keypress procedure.
\end{abstract}

\section{Results and Discussion}

In the first analysis, line within the passage (1-20) was used as a variable. Although some variance was consumed by changes in reading times as the reader progressed through the text, this variable did not interact in any interesting way with the main factors (i.e., group, condition, and difficulty). For this reason, the data were collapsed across lines 1-20 and all analyses were conducted on those total reading times. The reading times for the second readings were analyzed for the effects of group (high/low ability), difficulty (easy/difficult passages), and condition (first reading normal or scrambled). The main effects were qualified by the interaction of group with difficulty $\left[F(1,46)=4.11, M S_{\mathrm{e}}=50.76, p<.05\right]$, so the data for high- and low-ability readers were analyzed separately in $2 \times 2$ analyses of variance, looking at the effects of difficulty and condition for each reader group. For the high-ability readers, easy passages were read faster than difficult passages $\left[F(1,23)=48.64, M S_{\mathrm{e}}=53.17\right.$, $p<.001$ ] , and second readings were faster following first readings of the normal as opposed to the scrambled versions $\left[F(1,23)=9.70, M S_{\mathrm{e}}=95.75, p<.01\right]$. The interaction was marginal $\left[F(1,23)=3.55, M S_{\mathrm{e}}=39.07\right.$, $p<.07]$. As Table 2 shows, this marginal effect results from the somewhat larger difference between conditions for the difficult as opposed to the easy passages. The critical question here, however, is whether there was reliable transfer from the first reading to these second readings. To gauge these transfer benefits, the savings comparisons used in Experiment 1 were conducted here. That is, the time of each second reading (always of normal passages) was compared with the reading time for the normal passage when it was read first. For these high-ability readers, there was reliable transfer in the normal condition for both easy $[t(23)=5.25, p<.001]$ and difficult $[t(23)=$ $5.81, p<.001]$ passages. However, in the scrambled condition, there was no reliable transfer for either level of difficulty $(t \mathrm{~s}<2, p \mathrm{~s}>.1)$. These results are consistent with earlier work showing transfer mediated at the text level, with no reliable transfer at the single-word level. For these high-ability readers, this general finding held even for the more difficult passages.

For the low-ability readers, however, the results were somewhat different. In the $2 \times 2$ analysis of the second reading times, easy passages were read faster than difficult ones $\left[F(1,23)=105.12, M S_{\mathrm{e}}=48.34, p<.001\right]$, and second readings were faster following the first reading of a normal as opposed to a scrambled version $[F(1,23)=$ $\left.7.73, M S_{\mathrm{e}}=7.74, p<.01\right]$. The interaction did not approach reliability. The analyses measuring the reliability of transfer to the second reading indicated that again there was transfer from the first reading of a normal text for both easy $[t(23)=5.75, p<.001]$ and difficult $[t(23)=$ $8.63, p<.001]$ passages. Thus, like the high-ability read- 
ers, these low-ability readers benefited from the repetition of intact passages. The interesting result was that these low-ability readers also showed reliable transfer in the scrambled condition for both easy $[t(23)=2.40, p<.01]$ and difficult $[t(23)=1.90, p<.05]$ stories. Furthermore, there was no reliable difference in the amount of transfer found in the scrambled and normal conditions when the stories were difficult $[t(23)=1.11, p>.1]$. Thus, these low-ability adult readers showed the same word-level transfer as that reported by Carr et al. (1989), and the word-level transfer matched the text-level transfer when the texts were challenging, just as Carr et al. reported. Thus Experiment 2 replicated the Carr et al. findings and the mechanism that produced this result became clearer. When the texts are difficult for the readers' skill level, attention is focused on word recognition, and transfer is then mediated by these lower level word representations. This is found in the less skilled readers, not in the skilled readers, suggesting that it is indeed a form of nonfluent transfer. The highly skilled readers show the fluent transfer that is mediated at the text level. Experiment 2, then, demonstrated the two types of transfer in adults that were demonstrated in Experiment 1 for children.

\section{GENERAL DISCUSSION}

The two experiments reported here show that both word- and text-level representations can mediate rereading transfer. In Experiment 1, transfer at the text level, with no transfer at the single-word level, that has been reported for fluent adult readers (Levy \& Burns, 1990) was replicated with good readers in Grade 4. However, poor readers in Grade 4 for whom the stories were difficult showed transfer at the single-word level as well, replicating the results in Faulkner and Levy (1994), but obtained with the use of the repeated readings manipulation that has been extensively studied in the adult literature. The results suggest that two forms of transfer are related to the fluency of reading. If the reader is reading fluently (quickly and accurately), transfer appears to be mediated largely by text-level processes. However, if the text is difficult for the reader and he/she is unable to read it fluently, transfer at the single-word level occurs (as found with adult subjects by Carlson et al., 1991; Carr et al., 1989). This notion that there are fluent and nonfluent forms of transfer was tested further in Experiment 2, in which adult readers with high or low reading ability were asked to read easy and difficult materials. The high-ability readers had no difficulty in fluently processing either type of material, and they showed only text-level transfer with no benefit from a prior reading of the words with no text structure. These findings replicate those reported by Levy and her colleagues (Levy \& Burns, 1990; Levy et al., 1995; Levy \& Kirsner, 1989; Levy et al., 1991). However, the low-ability readers showed word-level transfer as well, which increased as the materials became more difficult to read. These findings resemble those reported by Carr et al. (1989), and they are consistent with the focus of attention view which suggests that when attention is focused on the word level, transfer in rereading will be mediated by word-level representations (Carlson et al., 1991).

Thus, the debate about the level of representation involved in rereading transfer is resolved if one focuses on the fluency of word recognition, which is determined by the difficulty of the text relative to the reader's ability. When adult readers are reading in a fluent fashion, because the texts are at their reading level, then the reader focuses attention on the message, and transfer is mediated at that level. However, when the adult reader is forced to read in a word-by-word fashion, either through instructions (Carlson et al., 1991) or when the texts are difficult for them (Experiment 2), then the focus of attention during reading is at the word processing level and all transfer to later readings must also be at that level. This same fluent/nonfluent contrast can be seen with good and poor readers in grade school, where the development of fluency can be seen more naturally. The main point of this distinction is that repetition effects in reading can be mediated at various levels, but fluent rereading is mediated by text representations. When one is interested in the developmental stages that lead to fluency, word-level transfer is important. This may represent an early stage of development when word recognition itself must become automated so that attention is no longer focused at this level. Through practice (repetition), these lexical representations can be accessed automatically, and then attention can be focused on message processing. When reading is developed to this level, or when it is this fluent, the words become integrated into the text representation and that representation mediates transfer. Levy (1993) argued that the words are part of this representation but that they are contextually bound to the representation and cannot mediate rereading transfer unless the text representation itself can be recruited. This can only occur when the rereading task also involves the message levels; words without their context cannot recruit a textlevel representation. Thus, transfer in fluent reading requires some message overlap in order to access previously laid down meaningful representations.

\section{REFERENCES}

Carlson, L. A., Alejano, A. R., \& Carr, T. H. (1991). The level-offocal-attention hypothesis in oral reading: Influences of strategies on the context specificity of lexical repetition effects. Journal of Experimental Psychology: Learning. Memory, \& Cognition, 17, 924-931.

Carr, T. H., Brown, J. S., \& Charalambous, A. (1989). Repetition and reading: Perceptual encoding mechanisms are very abstract but not very interactive. Journal of Experimental Psychology: Learning. Memory, \& Cognition, 15, 763-778.

Cohen, N. J., \& SQuire, L. R. (1980). Preserved learning and retention of pattern analyzing skill in amnesia: Dissociation of knowing how and knowing that. Science, 210, 207-209.

DAHL, P. R. (1979). An experimental program for teaching high speed word recognition and comprehension skills. In J. E. Button, T. C. 
Lovitt, \& T. D. Rowland (Eds.), Communications research in learning disabilities and mental retardation (pp. 33-65). Baltimore: University Park Press.

DOWHOWER, S. L. (1987). Effects of repeated reading on second-grade transitional readers' fluency and comprehension. Reading Research Quarterly, 22, 389-406.

FAULKNER, H. J., \& LEVY, B. A. (1994). How text difficulty and reader skill interact to produce differential reliance on word and content overlap in reading transfer. Journal of Experimental Child Psychology, 58, $1-24$.

FLESCH, R. F. (1948). A new readability yardstick. Journal of Applied Psychology, 32, 221-223.

KoLERS, P. A. (1975). Memorial consequences of automatized encoding. Journal of Experimental Psychology: Human Learning \& Memory, 1 , 689-701.

LEVY, B. A. (1993). Fluent rereading: An indirect indicator of reading skill development. In P. Graf \& M. E. J. Masson (Eds.), Indirect memory: New directions in cognition, development, and neuropsychology (pp. 49-73). Hillsdale, NJ: Erlbaum.

LEVY, B. A., \& BuRNS, K. I. (1990). Reprocessing text: Contributions from top-down processes. Canadian Journal of Psychology, 6, 293-323.

Levy, B. A., Campsall, J., Browne, J., Cooper, D., Waterhouse, C., \& WILSON, C. (1995). Reading fluency: Episodic integration across texts. Journal of Experimental Psychology: Learning, Memory, \& Cognition, 21, 1169-1185.

LEVY, B. A., \& KiRSNER, K. (1989). Reprocessing text: Indirect measures of word and message level processes. Journal of Experimental Psychology: Learning, Memory, \& Cognition, 15, 407-417.

Levy, B. A., Masson, M. E. J., \& ZoubeK, M. A. (1991). Rereading text: Words and their context. Canadian Journal of Psychology, 45, 492-506.

Oliphant, G. W. (1983). Repetition and recency effects in word recognition. Australian Journal of Psychology, 35, 393-403.

Rashotte, C. A., \& Torgesen, J. K. (1985). Repeated reading and reading fluency in learning disabled children. Reading Research Quarterly, 20, 180-202.

SAmuels, S. J. (1979). The method of repeated readings. The Reading Teacher, 32, 403-408.

\section{NOTES}

1. A third condition with scrambled sentences was included in the design, but these data are not relevant to the word versus message comparisons that are the focus of this paper. Consequently those data are not discussed here.

2. A third condition was included in the design, in which the first reading was a scrambled word version of a passage unrelated to the passage read second. This condition provided another baseline for comparisons of second reading times. The results obtained by using this baseline to measure amount of transfer on the second reading yielded the same pattern of results as those obtained using the reading time of the normal text on the first reading. We report the data in terms of the savings from Reading 1 to Reading 2 here to be consistent with the analysis of Experiment 1 .

(Manuscript received July 22, 1997; revision accepted for publication March 26, 1998.) 